Cadernos de Arquitetura e Urbanismo, v.17, n.21, 20 sem. 2010 
1. Trabalho de conclusão de curso apresentado à disciplina Filosofia Contemporânea II, do Curso de Especialização em Temas Filosóficos, da Faculdade de Filosofia e Ciências Humanas da UFMG $-2008 / 02$.

2. Especialista em Temas Filosóficos (UFMG), arquiteto e urbanista (Fumec). 


\title{
A PRODUÇÃO \\ ARQUITETOONICA E SUA \\ RELAÇÃO COM O PODER
}

ARCHITECTURAL DESIGN AND ITS RELATION WITH POWER

Gustavo Henrique Maciel Camargo²

A arquitetura não pode ser concebida senão como uma prática social, figurando com outras (por exemplo, a medicina), no conjunto prático que sustenta e suporta a sociedade atual (o modo de produção). (LEFEBVRE, 2008)

\section{Resumo}

Tomando como base a leitura das obras Vigiar e punir (FOUCAULT, 2008) e Microfísica do poder (FOUCAULT, 2008), o objetivo do presente ensaio é apontar e tentar explicar algumas das representações formais da relação entre a produção arquitetônica e urbanística e as ideologias do poder responsáveis por sua produção, explicitando como a tais relações pode e deve ser atribuído o surgimento dos mais diferentes exemplos de edificações e de espaços urbanos que hoje conhecemos, bem como de suas transformações históricas.

Palavras-chave: Arquitetura; Urbanismo; Foucault.

\begin{abstract}
Based on Foucault's Discipline and punish and Microphysics of power, this essay points out and attempts to explain some of the formal manifestations resulting from the relation between architectural and urban design and the ideologies of power responsible for their production, showing how the development of various types of buildings and urban spaces that we know today, as well as their historical transformations, can and must be analyzed in terms of such relation.
\end{abstract}

Key words: Architecture; Urban design; Foucault. 
3. Segundo Indra Kagis McEwen, Dédalo foi o primeiro arquiteto de que se tem registro. O projeto do labirinto sob o Palácio de Knossos, na Grécia, é, segundo afirmação da autora, trabalho de Dédalo, comissionado pelo Rei Minos, supostamente para aprisionar o Minotauro (MCEWEN, 1993).

4. Referimo-nos às práticas da arquitetura e do planejamento urbano.
5. Segundo George Teyssot, na introdução do livro Flesh, de autoria dos arquitetos Elisabeth Diller e Ricardo Scoffidio: "Para começar, é perfeitamente possível imaginar a atividade, na arte ou arquitetura, como uma forma específica de reflexão sobre nossa situação contemporânea, isto é, 'nosso estar presente', atirados, projetados no mundo contemporâneo pelo destino. É exatamente porque a arquitetura tem a muito concreta e útil vocação de construir abrigos para a habitação, que ela também tem a obrigação e o direito de se autorreexaminar insistentemente".

Tradução nossa de parte do texto de introdução (DILLER; SCOFFIDIO, 1994).

Cadernos de Arquitetura e Utbanismo, v.17, n.21, 20 sem. 2010
Desde a existência de Dédalo, apontado como o primeiro arquiteto de que se tem notícia, ${ }^{3}$ é possível perceber que a prática da arquitetura exibe estreita relação com o poder, tenha ele qual forma tiver. Ao longo da história, fornecendo condições concretas de atuação à autoridade vigente, a arquitetura sempre refletiu as relações de poder que dominavam o cenário social e econômico que a engendrou. Tanto como estratégia de legitimação desse poder quanto como instrumento viabilizante de sua atuação, fosse por meio de obras arquitetônicas ou do próprio traçado urbano, essas duas práticas ${ }^{4}$ deviam, necessariamente, agregar e formalizar as premissas vigentes, sob pena de sacrificarem tanto a si próprias, como defende Ernest Gombrich, sobre a produção arquitetônica do século XVIII, quanto os próprios mecanismos de poder, conforme se pode verificar acerca das barricadas de Paris em 1848. As consequências da experiência revolucionária na capital francesa seriam responsáveis pela implantação do processo de "haussmannização" do espaço urbano e de gentrificação, notadamente das populações menos favorecidas, nas mais diversas partes do mundo, a América do Sul incluída.

A partir da Revolução Industrial, com o crescimento do contingente urbano e o surgimento de grandes aglomerados humanos, altera-se também a lógica do controle espacial. Essa alteração coloca na ordem do dia o papel da arquitetura e do planejamento urbano como ferramentas de produção, organização e controle da população cada vez mais adensada, o que faz dessas práticas, mais uma vez, ferramentas do poder. Por isso mesmo, o papel, tanto de uma como de outra, representa, mais do que nunca, meio válido para a análise e compreensão, além das estratégias de controle do poder imediatamente relacionado à sua produção, da própria natureza atual desse poder no espaço. Especula-se aqui que a análise minuciosa do movimento formal dessas duas práticas, com seus mais diversos desdobramentos contemporâneos, possibilitaria a compreensão das modificações nas próprias estruturas de poder.

O desenvolvimento das práticas arquitetônica e urbanística, as quais o presente ensaio tentará abordar, quando analisado à luz da teoria foucaultiana, notadamente aquela contida nas duas obras citadas acima, permite explicitar como tais atividades, para além de simples obras das estruturas de "poder", conforme definido por Foucault, apud Revel, segundo o qual o poder não parece ser mais do que a capacidade que alguém ou algo possui de fazer com que outra pessoa ou coisa atue de forma preestabelecida (REVEL, 2005), representam ferramentas, tanto para sua legitimação quanto para sua perpetuação, estabelecendo, dessa forma, um círculo vicioso entre arquitetura e poder, no interior do qual algumas das práticas da arquitetura e do planejamento urbano operam como ferramentas que servem às estruturas que as geram, e cuja premissa principal passa a ser, por parte dessas mesmas práticas, a de tirar proveito, com intenção de autoperpetuação.

Se concordarmos, por um lado, com a afirmação de Foucault acerca do poder como algo "não unitário e global", como uma prática social, constituída historicamente (FOUCAULT, 2008b), e por outro, com as palavras de George Teyssot ${ }^{5}$ sobre o papel da arquitetura, expandido para outros domínios e tipologias além da 
6. Ainda que aplicado a edificações e traçados urbanos antigos, o conceito aqui utilizado de "urbanístico" funda-se, principalmente, naquele defendido por Lefebvre acerca da cidade contemporânea, que ele afirma representar uma "projeção em solo das relações de poder vigentes" (LEFEBVRE, 2004).

7. Entre as três pirâmides mais representativas, e a de maiores dimensões, a do faraó Quéops, cujo reinado e período de edificação do legado arquitetônico se deram entre 2553 e 2530

a.C., era considerada pelos gregos uma das sete maravilhas do mundo. Foi sobre

a magnitude dessa obra que Napoleão Bonaparte, ao olhá-la, disse aos seus soldados: "Do alto dessas pirâmides quarenta séculos vos contemplam" (HAGEN, 1999).

8. Entre 2553 e 2486 a.C. (HAGEN, 1999).

Cadernos de Arquitetura e Urbanismo, v.17, n.21, $2^{0}$ sem. 2010 habitação, uma das primeiras questões que surgem diz respeito às formas através das quais a própria arquitetura vem, ao longo dos séculos, respondendo às condições históricas e sociais que, por um lado, legitimam, e por outro permitem a prática social do atributo aqui definido como poder. Em outras palavras, quais foram ou são as respostas formais que a arquitetura forneceu às alterações das condicionantes históricas que, de alguma maneira, viabilizaram, reiteraram ou permitiram a prática social desse poder? Mais uma questão que se faz presente tem relação com a extensão da influência que o próprio desenvolvimento das técnicas arquitetônicas teve e tem no estabelecimento das condições de possibilidade históricas legitimadoras da prática social do poder. Em outras palavras, até que ponto a produção arquitetônica opera como simples recodificadora de um poder que, já existindo, é capaz de se perpetuar, e a partir de que ponto essa mesma produção passa a servir como condição de possibilidade para que esse mesmo poder venha a se viabilizar?

\section{A ligação atemporal entre a arquitetura, 0 urbanismo e as estruturas de poder}

A leitura de textos arquitetônicos e urbanísticos ${ }^{6}$ revela que, com efeito, a produção arquitetônica disponível para estudo, notadamente quando o fazemos sobre edificações e formações urbanas não contemporâneas, está associada, em sua vasta maioria, às classes detentoras de poder contemporâneas das edificações descritas. Muito se sabe sobre as pirâmides do Egito, por exemplo, as quais, ainda que reinterpretadas sob o olhar do século $X X I$, permaneceram virtualmente intactas, ao longo de mais de quarenta séculos. ${ }^{7}$ Ao contrário, quase tudo o que faz referência às edificações das populações hierarquicamente mais baixas, ou seja, possuidoras de menor poder, durante o mesmo período histórico da produção das pirâmides, ${ }^{8}$ gravita no universo da especulação, exibindo poucas evidências objetivas. Sobre o exemplo da civilização egípcia, poderíamos afirmar que o estudo das manifestações formais, tanto da produção arquitetônica quanto da urbanística dessa civilização representa, de fato, uma tentativa de interpretação dessa civilização sob o olhar dos donos do poder, cujas obras foram feitas para resistir à passagem do tempo, como afirmou o próprio Foucault, "recodificando" ininterruptamente esse mesmo poder. Além disso, essa recodificação implica, no caso em questão e em mesma proporção, uma descodificação dos signos e produção do restante dos demais estratos dessa sociedade, o que significa dizer, em termos práticos, o seu esvaziamento e desaparecimento material e imaterial. Aqui vale citar Lefebvre, para quem "excluir do urbano grupos, classes, indivíduos, implica também excluí-los da civilização, até mesmo da sociedade" (LEFEBVRE, 2008, p. 32). Tal estratégia, levada a fim e a termo por meio de decisões que incluíam local de implantação, escolha de materiais, técnica mobilizada para a edificação etc., sempre buscou, por um lado, "inflar" o próprio poder que comissionara a obra, enquanto, concomitantemente, contribuía para "esvaziar" o poder físico que, em última instância, havia sido incumbido de sua execução. Dessa forma, tais estratos hierarquicamente inferiores, tão representativos quanto os hierarquicamente superiores, em termos de compreensão da 
unidade cultural, são, através do desaparecimento de sua produção arquitetônica, expurgados da análise póstuma. O desaparecimento das edificações de caráter "hierarquicamente inferior" da sociedade egípcia é altamente indicativo das possíveis manifestações que a produção arquitetônica proporciona às estruturas de poder. Isso significa dizer que, em termos de produção arquitetônica, a obra edificada, não apenas no caso do Egito antigo, mas também no de diversas outras civilizações e períodos históricos, desde a sua concepção, visa a recodificar e perpetuar as relações de poder capazes de aglutinar os meios necessários para sua execução, mas não as forças que os executaram, em termos físicos propriamente ditos. Aparentemente, já se encontrava em vigor, desde então, uma estrutura parecida com o que Foucault definiria como o foco de interesse do exercício do poder, qual seja, "aumentar a utilidade econômica e diminuir os inconvenientes, os perigos políticos; aumentar a força econômica e diminuir a força política" (FOUCAULTa, 2008, p. XVI).

Essa seria a condição dominante até a segunda metade do século $\mathrm{XV}$, com o lançamento da obra $\mathrm{A}$ vida dos mais extraordinários pintores, escultores e arquitetos, de Giorgio Vasari (2006), a partir da qual a autoria dos "projetos arquitetônicos" passa a ser, objetivamente, atribuída a alguém. Tal transformação de atitude, por si só, pode ser indicativa de uma alteração na estrutura de poder, na medida em que o trabalho artístico passa vagarosamente a ser reconhecido como de caráter intelectual, fato que atribui valor e consequentemente poder àqueles que o concebiam. Essa conclusão corrobora aquela exposta por Foucault: "O poder é algo que se exerce, que se efetua, que funciona. E que funciona como uma maquinaria, como uma máquina social que não está situada em um lugar privilegiado ou exclusivo, mas se dissemina por toda a estrutura social" (FOUCAULTa, 2008, p. XIV).

Até o século XVIII, a resposta formal que a arquitetura proporcionava visava a satisfazer duas solicitações principais, a exibição do poder e a punição dos "contraventores", ou seja, aqueles que agrediam ou ofendiam a estrutura dominante, em diferentes graus. Nesse aspecto, dois dos mais ricos exemplos de utilização da arquitetura como ferramenta dedicada a tais fins vêm da França. O primeiro deles tem relação com a estratégia de apropriação da produção arquitetônica, com intenção de implantação do processo a que Foucault chama de "recodificação" do poder, por meio da sua exibição e ostentação. Sob esse aspecto, o registro dos legados dos reinados de Luís XIV, XV e XVI, compreendidos, individualmente, entre 1643 e 1791, é representativo. Para além do fato de cada um dos períodos estar esteticamente associado a um estilo decorativo específico (o reinado de Luís XIV ao estilo barroco, o de Luís XV, ao regência, e o de Luís XVI ao rococó, cada um com características distintas, tais como desenho de mobiliário, uso de cores e materiais, distribuição espacial etc.), o ritmo de construção, as necessidades de manutenção e a crescente sofisticação das edificações, palácios, casas de campo e castelos, com posterior demolição e substituição de parte ou mesmo da totalidade dos edifícios, foram responsáveis, segundo Christine Pevitt Algrand, pelo consumo de cerca de 10\% do total do PIB francês, dedicados a esse fim em orçamento, para o ano de 1754 (ALGRAND, 2005, p. 267). 
9. É o que afirma Hobsbawm em seu livro A revolução francesa (1996).
O segundo dos grandes símbolos do poder absolutista, a fortaleza da Bastilha, possivelmente o mais eloquente acerca das práticas punitivas efetivadas pelas estruturas dominantes então, representava, no imaginário da população, a edificação no interior da qual a punição era, de fato, desregrada e absoluta, operando também com estrutura de recodificação do poder. A deflagração da Revolução Francesa, com a tomada dessa prisão em julho de 1789, ainda que esta, supostamente na data do ataque abrigasse apenas sete prisioneiros, ${ }^{9}$ tornar-se-ia altamente indicativa, por um lado, das evidências do início da transformação da infraestrutura dedicada ao poder, na medida em que este transitava entre classes, passando da aristocracia para a burguesia, e por outro, da própria necessidade de transformação, com base no fato de que a infraestrutura dedicada ao exercício do poder, cujas premissas principais eram se exibir (recodificar-se) e punir, não mais era capaz de conservar a situação, a esse ponto, caracteristicamente urbana, em oposição à anterior, eminentemente rural, com capacidade de mobilização social reduzida e, por isso mesmo, sob controle. Principalmente na França, os fatos entre 1789, ano da Revolução Francesa, por um lado, e 1848, ano das barricadas na mesma cidade, as quais finalmente explicitaram a perda do controle sobre o espaço e sobre a movimentação do corpo no espaço, por outro passariam à história como exemplos da transformação espacial, a qual, caso quisesse se perpetuar, a estrutura de poder deveria efetuar, de forma a conservar o controle, tanto do espaço como do corpo no espaço. Essa transformação ocorreu principalmente em função de condicionantes históricas postas pela Revolução Industrial, notadamente o surgimento de uma massa de trabalhadores e consumidores, aglomeração necessária ao florescimento da sociedade de consumo. Tanto a concentração de corpos no espaço quanto a alteração das premissas de utilização desses corpos serviram como gatilho para que, mais uma vez, com base na utilização da arquitetura e do planejamento urbano como ferramentas, a estrutura de poder fosse capaz de alterar suas táticas de concepção espacial, em termos arquitetônicos e urbanísticos.

Essa transição, que se pode observar por meio da análise de Foucault sobre as manifestações do poder, sobretudo entre os séculos XVII e XIX, indica um claro processo de desmaterialização, tanto das táticas de atuação quanto da própria presença que esse mesmo poder passava a assumir, conforme afirma o filósofo, "mais discretos, mais insidiosos e eficientes" (FOUCAULTb, 2008, p. 122). Com essa alteração, ainda que a premissa da recodificação por meio da exibição continuasse a atuar, a da punição viria, também em termos arquitetônicos e urbanísticos, a ser substituída pela do controle, percebida, a partir de então, em decorrência dos níveis de aglomeração humana, como mais eficiente. Mais uma vez, essas duas atividades se prestariam, como importantes ferramentas, ao restabelecimento do controle sobre o corpo e o espaço, com o intuito de permitir a aplicação prática das novas premissas.

É possível percebermos, também nessas duas ferramentas, da mesma forma que nas estratégias do poder, uma busca da substituição da sensação de onipotência que o poder exibia até então, haja vista as cerimônias dos suplícios, por uma de onipre- 
10. De acordo com Christine Pevitt Algrand, em sua biografia sobre Madame de Pompadour, Robert François Damiens, um sujeito natural de Artois, atacou e feriu, com uma pequena faca, o rei Luís $X V$, quando este passeava, em companhia de seu séquito, pelo Trianon. Ainda de acordo com a autora, Damiens foi acusado de parricídio, à época incluído entre os crimes que exigiam a pena capital. $\mathrm{O}$ ataque aconteceu em 6 de janeiro de 1757 e a execução do criminoso, em frente ao Hôtel de Ville, em Paris, no dia 2 de maio do mesmo ano (ALGRAND, 2005). sença velada, despida de qualquer intenção de opressão, mas de controle e de disciplina. Ao descrever a ocorrência de uma cerimônia de suplício, como, por exemplo, a de Damiens, ${ }^{10}$ o filósofo afirma que, para além de punir, a intenção do suplício era vingar a ofensa perpetrada contra a pessoa do rei, ao declarar, sobre os reformadores do século XVIII, que eles denunciaram: "O que excede, de um lado e de outro, o exercício legítimo do poder: a tirania, segundo eles, se opõe à revolta. Elas se reclamam reciprocamente. Duplo perigo. É preciso que a justiça criminal puna em vez de se vingar" (FOUCAULTb, 2008).

Na medida em que a principal tipologia arquitetônica dedicada à punição, à época da execução de Damiens, era representada pela masmorra, não surpreende, em comparação com os fatores que colocaram em movimento essa busca de renovação das estratégias de controle da população, que essa mesma população, ao se rebelar contra esse poder, pouco mais de trinta anos depois, tenha tomado seu símbolo maior na capital francesa, a Bastilha. À tomada da Bastilha, como forma de sublevação contra a dominação vigente, seguiu-se a tomada de diversas outras edificações, notadamente palácios e castelos, como o de Belle Vue, localizado próximo de Paris, também vistos como variações dos mecanismos vigentes de dominação. Era exatamente acerca das alterações das condicionantes espaciais que permitiam o exercício do poder então que os teóricos do final do século XVIII alertavam, ao afirmar que ao continuar o terror, menos do que fazer justiça, o que o suplício realizava era a "reativação do poder", prática que pertencia a uma outra época (FOUCAULTa, 2008 , p. 43), aqui compreendida como uma de aglomerações humanas menores, com capacidade de organização e de destruição reduzidas, frente às forças que as controlavam. Em face dessas forças, tornava-se necessário que tanto as manifestações desse poder quanto a materialização espacial dessa mesma força se alterassem, de forma a conservar sua efetividade sobre a população e, por extensão, sobre o espaço urbano. Compreende-se, então, que tal alteração deveria passar ao campo do monitoramento contínuo do movimento dos corpos no espaço, além do controle sobre o próprio espaço. Caracterizada, segundo a teoria foucaultiana, como o "investimento no corpo", tal mudança de curso viria abrir caminho para alterações radicais, tanto do espaço edificado, quanto das próprias edificações. Caem por terra as premissas que haviam vigorado até então, e que faziam da masmorra sua principal tipologia. A tríade esconder, privar de luz e restringir os movimentos, com a intenção de punir, é substituída pelo seu oposto, qual seja, exibir, expor à luz e libertar os movimentos, dedicados ao controle. Abria-se, assim, o caminho para que todo o espaço, incluindo o interior das próprias edificações, fosse compreendido como campo de atuação do poder e sofresse também sua adequação às novas estratégias. Sob esse aspecto, as aglomerações urbanas assistem ao processo de capilarização das estruturas coercitivas. No caso da cidade de Paris, essa nova lógica de organização do espaço seria a responsável pelo surgimento do processo de haussmannização do espaço público, notadamente com a intenção de aprimoramento dos mecanismos de controle, tanto sobre esse espaço quanto sobre a movimentação dos corpos nele. Tal processo incluía a demolição de antigas edificações, a eliminação de focos de orga- 
nização espacial que propiciassem a sublevação, ou mesmo que impedissem sua extinção imediata, caracteristicamente com base na implantação de grandes bulevares, cuja intenção era, por um lado, garantir o acesso imediato da polícia aos pontos de conflito, ao mesmo tempo em que restringia a possibilidade de barricadas nessas mesmas vias. Todas as obras eram executadas sob a bandeira da modernização e do embelezamento, ainda que sob protesto de parte da população, para quem tal reforma era patrocinada pela "poderosa sociedade da imobiliária do Boulevard Haussmann, sustentada pelos vereadores e, por detrás deles, por grandes negócios como as Galeries Lafayette e, provavelmente, por um consórcio secreto de todos os comerciantes do bairro" (ARAGON, 1996, p. 55).

Pode-se perceber, por meio da afirmação de alguns dos habitantes da Passagem da Ópera, que a iniciativa de transformação do espaço urbano, por um lado, não partira do proletariado, e por outro, não contava com a aprovação deste.

Essas transformações espaciais decorrentes das alterações nas próprias estruturas de poder seriam responsáveis, no caso da Inglaterra, pelo surgimento de diversas correntes urbanísticas ao longo do século XIX, sob a égide da melhoria das condições de habitação e de trabalho da população. Em uma cidade como Londres, na primeira metade do século XIX, na qual cerca de cinquenta mil pessoas começavam o dia sem saber onde passariam a noite seguinte (ENGELS, 2004), a atuação, tanto do urbanismo como da arquitetura, foi fundamental, de maneira a exercer todas as formas de controle sobre o aglomerado humano. Para o capitalismo que se consolidava, tornava-se premente o controle sobre o que Gombrich descrevia como "um aglomerado de corpos humanos [...] homens, mulheres e crianças vivendo como animais, sem higiene e em locais insalubres [...] submetidos às piores condições de trabalho" (GOMBRICH, 2000). Esse meio serviria como base para o surgimento do panóptico de Jeremy Bentham ou das teorias de Ebenezer Howard e sua cidade-jardim, técnicas ligadas às disciplinas, as quais, segundo Foucault, representavam:

[...] técnicas sempre minuciosas, muitas vezes íntimas, mas que têm sua importância: porque definem um certo modo de investimento político e detalhado do corpo, uma nova "microfísica" do poder; e porque não cessaram, desde o século XVII, de ganhar campos cada vez mais vastos, como se tendessem a cobrir o corpo social inteiro. (FOUCAULTa, 2008, p. 120)

O planejamento urbano seria empregado, tanto na França quanto na Inglaterra, de maneira sistemática, para a criação e a manutenção das adequadas relações entre os grupos que compunham a nova realidade do meio sobre o qual o poder deveria atuar. A própria ascensão do planejamento urbano à condição de ciência deveu-se ao fato de que, como se encontrava conformada, a sociedade urbana dos séculos XVIII e XIX passara a ser fonte de criação de conhecimento acerca das novas necessidades e possibilidades de controle do espaço urbano. Conforme afirma Foucault: "O quadro, no século XVIII, é ao mesmo tempo uma técnica de poder e um processo de saber. Trata-se de organizar o 
múltiplo, de se obter um instrumento para percorrê-lo e dominálo; trata-se de impor uma ordem" (FOUCAULTa, 2008, p. 127).

Uma das estratégias de implantação e manutenção de tal "ordem" fazia uso do "quadriculamento" do espaço que, segundo o filósofo, visava a estabelecer "cada indivíduo no seu lugar; e em cada lugar, um indivíduo" (FOUCAULTb, 2008, p. 123). Surge, em consequência dessa nova estratégia, uma nova utilização espacial para o traçado hipodâmico das cidades, a partir do qual o "princípio da localização imediata", instaurado pelo quadriculamento como estratégia de controle dos corpos no espaço, passaria a ser exercido de maneira mais eficiente. Podemos perceber, então, uma significante alteração da abordagem da produção do espaço urbano, a partir do século XIX, com a "cientifização" das práticas, unicamente com a intenção de perpetuação do poder que, para sua efetivação, certamente dependia do controle desse espaço. Ainda que essa alteração fosse apresentada de maneira velada, geralmente vestida com as cores do neopositivismo e de suas políticas de planejamento urbano próprias, ela já configurava uma manifestação formal da transformação que a mudança dos aglomerados urbanos exigia. Admitida como verdadeira a premissa de que somente aquilo ou aquele que, investido por condicionantes históricas econômicas e/ou sociais, pode, de alguma forma e em certo grau, controlar algo ou alguém, ou seja, exercer o poder, mais uma vez podemos afirmar que a teoria de Michel Foucault e a produção arquitetônica e urbanística detêm estreita ligação. Sua materialização é evidência disso. Conforme afirma Lefebvre, "o espaço não é apenas organizado e instituído. Ele também é modelado, apropriado por este ou aquele grupo, segundo suas exigências, sua ética e sua estética, ou seja, sua ideologia" (LEFEBVRE, 2008).

Figura $1 \cdot$ A análise da transformação do centro antigo de Paris permite a visualização da transformação da estrutura de poder, da condição de onipotente, para a de onipresente. Figura: A haussmannização do centro de Paris.

Fonte: http://mapsof.net/uploads/ static-maps/paris_haussmann_ centre.png. Acesso em: 20 set. 2009.

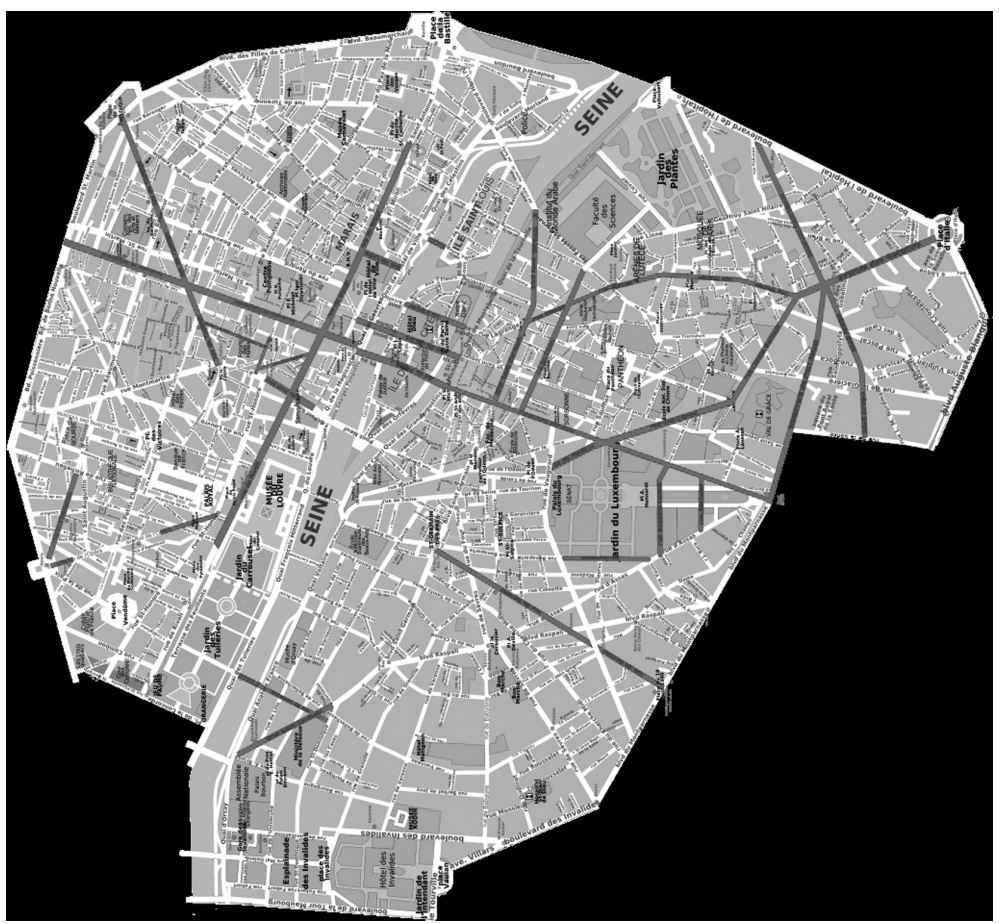

Cadernos de Arquitetura e Urbanismo, v.17, n.21, $2^{0}$ sem. 2010 
11. De acordo com Le Corbusier, esses cinco itens eram: 1) janelas em fita; 2) terraço jardim; 3) planta livre; 4) pilotis e 5) fachadas livres (LE CORBUSIER, 2002).

12. 31 Rue St-Guillaume, Paris, França. Autoria dos arquitetos Pierre Charreau e Bernard Bijvoet, além de Louis Dalbet, artesão

Cadernos de Arquitetura e Urbanismo, v.17, n.21, $2^{0}$ sem. 2010
No campo da manifestação arquitetônica propriamente dita, uma das transformações mais facilmente perceptíveis, e que surgiram em decorrência da alteração nas estruturas de poder entre os séculos XVIII e XIX, diz respeito à fenestração dos edifícios. Ainda que essa transformação formal tenha tido início efetivo durante o Renascimento, foi apenas ao longo do período citado acima que, de fato, as aberturas das fachadas se transformaram, sobretudo a partir da segunda metade do século XIX, com o desenvolvimento de novas técnicas construtivas e o emprego de novos materiais (HOLLANDA, 2002). Se, até por volta desse período, a grande maioria das edificações era caracterizada por aberturas pequenas, que escondiam seu interior, a partir de então, esses mesmos interiores passariam a serem exibidos, por meio de janelas cada vez maiores, culminando nos panos de vidro, desenvolvimento de um dos cinco itens principais da doutrina modernista, ${ }^{11}$ já em aplicação na primeira metade do século XX. Como estratégia de estabelecimento das disciplinas, para as quais o desenvolvimento, tanto das técnicas quanto dos materiais disponíveis para a construção, largamente contribuiu, e cujo principal alvo era o corpo, a revelação do interior das edificações provou ser excelente estratégia para a conformação de padrões disciplinares, bem como para sua manutenção. A abertura do interior das edificações permitiu a capilarização dos mecanismos de controle que, dessa forma, associavam-se à sua atuação no espaço público, universo caracteristicamente controlado pelo planejamento urbano, de forma a, conjuntamente, produzirem aquilo que Foucault definiria como meta das disciplinas, qual seja, a criação de "uma arte do corpo humano, que visa não unicamente o aumento de suas habilidades, nem tampouco aprofundar sua sujeição, mas a formação de uma relação que no mesmo mecanismo o torna tanto mais obediente quanto é mais útil, e inversamente" (FOUCAULT, 2008a, p. 119).

Além da abertura propriamente dita dos edifícios, a própria busca pela integração visual de espaços internos, almejada desde o final do século XIX, e à qual o desenvolvimento tecnológico também atenderia, é outra das manifestações presentes na produção arquitetônica. Desde o advento da utilização do ferro e do vidro na execução de edificações, introduzida de maneira sistemática entre o final do século XIX e o começo do XX, o interior delas se revelava, tanto para o exterior como para si próprio. Adolf Loos (1870-1933), um dos precursores dessa integração espacial entre ambientes, por exemplo, já buscava tal resultado em seus projetos, os primeiros deles concebidos ainda no começo do século XX em Viena, por meio da remoção de paredes, conexão visual vedada, ou mesmo aberturas sobre os panos da alvenaria, tanto interna quanto externa. O projeto da Maison de Verre, ${ }^{12}$ também do começo do século XX, já fazia, da mesma forma que os projetos de Loos, uso de materiais de introdução recente então, como os tijolos de vidro e painéis basculantes internos que, na casa parisiense, serviam para revelar, por meio de sua fachada translúcida, tanto o interior da edificação para o mundo exterior quanto seu interior para si próprio, fato inaudito até um século antes. Percebe-se nitidamente, nesse período, como o desenvolvimento da produção arquitetônica volta-se para a elaboração de soluções que permitiam à estrutura de poder aprimorar sua estratégia de quadriculamento, por meio da penetração no inte- 
rior das edificações, e da própria reconfiguração de seus espaços internos, especificamente com o intuito de instalação do regime das disciplinas, para as quais:

Importa estabelecer as presenças e as ausências, saber onde e como encontrar os indivíduos, instaurar as comunicações úteis, interromper as outras, poder a cada instante vigiar o comportamento de cada um, apreciá-lo, sancioná-lo, medir as qualidades ou os méritos. (FOUCAULT, 2008a, p. 123)

Tais estratégias de integração espacial iriam dar nascimento a correntes como o funcionalismo e o modernismo, dois importantes momentos que se oferecem à análise acerca da resposta formal que essas práticas foram capazes de fornecer, frente às exigências das estruturas de poder. No aspecto arquitetônico, a Ville Savoy, de autoria de Le Corbusier, concebida em 1929 como residência familiar, é representativa da manifestação formal da concepção dos espaços como ferramenta das disciplinas. Com seus espaços integrados, rígida segregação de funções e preestabelecimento de percursos internos, ao longo dos quais se aplica uma determinada lógica panóptica, na medida em que todos veem a todos, a Ville Savoy constitui um excelente exemplo da capacidade que a produção arquitetônica exibe de fornecer mecanismos de controle, de acordo com a lógica de quadriculamento para disciplinarização dos corpos.

Ainda sobre a produção arquitetônica do início do século $X X$, outro momento de grande importância remete à Cozinha de Frankfurt, de autoria da arquiteta austríaca Margarete Schütte-Lihotzky (1897-2000). Segundo Adrian Forty, acerca da arquitetura doméstica do início do século XX:

A mudança mais importante no último século das ideias que constituem o lar talvez tenha sido a de seu papel de fonte do bem-estar moral para o de fonte de bem-estar físico, representada em termos visíveis por sua transformação de lugar de beleza em lugar de eficiência. (FORTY, 2005, p. 149)

É nesse ambiente, no qual, segundo Forty, "a casa que economiza trabalho [...] era uma resposta [...] às demandas de eficiência nacional" (FORTY, 2007), que o século XX vê surgir o projeto dessa Cozinha que, com sua proposta de uma peça pré-fabricada, que previa tanto a disposição dos elementos quanto dos próprios insumos, assim como visava a estabelecer os próprios fluxos dos usuários do espaço, além de ser concebida com base, não necessariamente em um usuário tipo, mas antes em um comportamento tipo, cujo telos era, com efeito, a maximização da "eficiência nacional" (FORTY, 2007), refletia a teoria taylorista, em voga durante o mesmo período. Karel Capek, em seu romance Rossum's universal robots (DILLER; SCOFFIDIO, 1994), já havia advertido a sociedade acerca do que poderia ser considerado talvez o grau máximo do desenvolvimento das disciplinas, a transformação do ser humano em autômato, ou robô. A tentativa de estabelecimento de fluxos e rotinas do usuário por parte da Cozinha remete a essa estratégia, ao mesmo tempo em que a produção em massa da instalação (aparentemente foram vendidas cerca de 10.000 unidades), em um momento de escassez 
habitacional na Alemanha, indica outra estratégia de penetração dos mecanismos de aplicação das disciplinas. De acordo com Foucault, acerca de sua teoria, aqui associada ao advento da Cozinha de Frankfurt:

$O$ ato é decomposto em seus elementos; é definida a posição do corpo, dos membros, das articulações; para cada movimento é determinada uma direção, uma amplitude, uma duração; é prescrita sua ordem de sucessão. O tempo penetra o corpo, e com ele todos os controles minuciosos do poder. (FOUCAULT, 2008a, p. 129)

\section{Arquitetura, urbanismo e poder no Brasil do século $X X$}

Além do exemplo clássico da apropriação realizada por JK da arquitetura, com intenção de recodificação de poder e de estabelecimento de um código de disciplinas, outros casos acerca da apropriação da produção arquitetônica e urbanística em solo brasileiro são também representativos. É clara, por trás de todo o discurso oficial governamental, a intenção do primeiro plano urbanístico desenvolvido para o Rio de Janeiro, o Plano Agache, de autoria do arquiteto francês Alfred Agache. Ainda que sua execução fosse dissimulada com base na necessidade de melhoria das condições de salubridade, notadamente do centro da cidade, suas reais intenções eram, de fato, reordenar o espaço público de uma cidade que via, cada vez mais, crescer a circulação de bens e mercadorias. Era a partir da experiência das barricadas de Paris, no século XIX, que, em solo brasileiro, a estrutura de poder buscou, por meio desse plano, redefinir seu domínio sobre o território da capital nacional. Conforme afirma Vera Rezende, "o espaço tem sido, ao longo do tempo, destinado a cumprir funções específicas que variam segundo as necessidades das organizações sociais em cada época" (REZENDE, 1982, p. 19).

Sob esse aspecto, a utilização do planejamento urbano no Rio assume, desde o seu início, o caráter disciplinar, na medida em que, de acordo com a mesma autora:

Um plano como esse programa alterações desejadas nos usos dos espaços e dos equipamentos urbanos sempre visando alcançar a cidade ideal, sem problemas de habitação e congestionamento de trânsito. Supõe, também, que as vidas dos habitantes da cidade são determinadas pelo entorno físico e, dentro do seu determinismo físico, se faz acreditar capaz de modificar o homem através da transformação dos ambientes. (REZENDE, 1982, p. 31)

Ainda segundo Rezende, N.W. Sodré apontava, a partir dos anos 1920, a necessidade de se "alterar o poder para que a burguesia realize as mudanças no aparelho de Estado convenientes aos seus interesses" (REZENDE, 1982). Observa-se, dessa forma, que a iniciativa de "modernização" da cidade do Rio de Janeiro tratava-se, de fato, de sua adequação a parâmetros aceitáveis para a circulação de bens e mercadorias, em uma cidade cuja população, já no início do século, contava cerca de quinhentos mil habitantes. Dito de outra forma, a transformação do centro do Rio de Janeiro via Plano Agache buscou a adequação do espaço 
13. Segundo afirma Ruy Castro, "em 1920 o morro do Castelo [...] foi arrasado a dinamite e jatos d'água, com praticamente tudo que havia em cima [...]. O argumento era de que o morro do Castelo dificultava a circulação do ar no centro da cidade" (CASTRO, 2007, p. 169).

14. Coincidentemente, a City of São Paulo Development Company acaba de retornar à atividade na cidade, com o planejamento e implantação de um bairro e um condomínio, o primeiro com área pouco maior do que a do Parque do Ibirapuera, localizado em Pirituba e o segundo no Morumbi, de acordo com artigo publicado no jornal Folha de S.

Paulo, do dia 13/9/2009.

15. O Dicionário Houaiss define sebe como uma "cerca de plantas ou de arbustos e ramos secos para proteger vinhas e quintais", elemento que denota, na verdade, menos a intenção de proteger do que de revelar o interior do perímetro dos lotes lindeiros (HOUAISS, 2001).

Cadernos de Arquitetura e Utrbanismo, v.17, n.21, $2^{0}$ sem. 2010 urbano às necessidades do capital estrangeiro, desconsiderando, ao longo desse processo, as vozes das camadas hierarquicamente menos favorecidas da população. ${ }^{13}$ Tal adequação incluía o estabelecimento de mecanismos de disciplina e vigilância, da mesma natureza daqueles implantados na Europa, durante o surto de haussmannização de suas maiores capitais. O plano subsequente, o Doxiadis, viria introduzir a noção de "estudos das comunidades com análise sobre o espaço" (REZENDE, 1982, p. 56), de forma que, já a partir do segundo plano urbanístico do Rio de Janeiro, em 1965, os mecanismos descritos por Foucault em sua obra Microfísica do poder, como o poder que gera conhecimento que, por sua vez, aplica esse conhecimento para sua própria perpetuação, podem ser vistos em ação no espaço carioca. Sua atuação visava à ampliação da capacidade de controle estatal sobre o espaço público, com a intenção de estabelecer as adequadas relações de poder. Mais uma vez, o desempenho de arquitetos e urbanistas busca proporcionar soluções formais às solicitações das estruturas de poder que os comissionam. O fato de ser o governo do Estado do Rio de Janeiro o principal interessado na implantação do Plano Doxiadis, quando historicamente contextualizado, concorda com a teoria de Foucault, segundo a qual "não se deve esquecer que a 'política' foi concebida como a continuação senão exata e diretamente da guerra, pelo menos do modelo militar como meio fundamental para prevenir o distúrbio civil" (FOUCAULT, 2008b, p. 141).

Ainda segundo o filósofo, na medida em que "o Estado não é o ponto de partida necessário, o foco absoluto que estaria na origem de todo tipo de poder social e do qual também se deveria partir para explicar a constituição dos saberes nas sociedades capitalistas" (FOUCAULT, 2008b, p. XIV), um exemplo em solo brasileiro que chama a atenção, tanto por haver se manifestado fora da estrutura do Estado, como por haver obtido êxito no estabelecimento de estratégias disciplinares que definiriam parâmetros para quase toda a produção do espaço urbano posterior à sua atuação é o caso da City of São Paulo Development Company, fundada no início do século XX. Barry Parker (1867-1947) e Raymond Unwin (1863-1940), ambos arquitetos urbanistas britânicos, foram os responsáveis por definir a transposição dos parâmetros urbanísticos ingleses para o solo paulistano, e que, em última instância, viriam a influenciar até mesmo os legisladores da cidade. Com projetos urbanos de características similares às da cidade-jardim, conceito originalmente desenvolvido especificamente para habitações da classe operária inglesa, e que remete diretamente a Ebenezer Howard (1850-1928), essa dupla de profissionais, atuante na São Paulo do começo do século XX, foi responsável pela implantação de grande parte dos bairros destinados à alta burguesia paulistana, entre 1902 e 1926, período de maior atuação da City na cidade ${ }^{14}$ (WOLFF, 2001). Sua atuação teve início com a implantação do bairro Jardim América, passou pelo Jardim Europa e concluiu-se com a implantação do Pacaembu. Com suas cercas baixas, quase sempre executadas em sebe, ${ }^{15}$ e algumas das quais ainda podem ser vistas nesse último bairro de implantação da City, é ele que mantém a maior quantidade de características originais do projeto. Os projetos urbanísticos propostos para a alta burguesia paulistana preservavam as estratégias espaciais atribuídas, segundo Michel Foucault, ao fato de que: 
A burguesia compreende perfeitamente que uma nova legislação ou uma nova constituição não serão suficientes para garantir sua hegemonia; ela compreende que deve inventar uma nova tecnologia que assegurará a irrigação dos efeitos do poder por todo o corpo social, até mesmo em suas menores partículas. (FOUCAULT, 2008a, p. 218)

Transportado para o solo paulistano pela City, o modelo de cidade-jardim inglês desempenharia papel importante no desenvolvimento da sociabilidade local, por meio da vigilância que, por sua vez, atuava como um dos mecanismos das disciplinas.

\section{Conclusão}

A análise da teoria foucaultiana acerca das estruturas de poder, quando sobrepostas à atuação da arquitetura e do planejamento urbano, indica que tais estruturas, a arquitetura e o planejamento do espaço urbano caminham pari passu. À transformação da estrutura de poder é possível atribuir uma reação específica, seja da produção arquitetônica, seja do planejamento urbano. No período em que as estruturas de poder necessitaram exibir sua onipotência, notadamente como estratégia de reconfiguração, sobretudo a arquitetura soube responder com edificações que traduziam tal sentimento. A solicitação, por parte do poder, de estruturas arquitetônicas dedicadas à punição gerou respostas arquitetônicas claras, responsáveis pelo surgimento da relação conhecida, por exemplo, entre a Bastilha ou a Torre de Londres e suas respectivas coletividades. Por outro lado, à transformação das estruturas de poder apontada por Foucault entre os séculos XVII e XIX, e a partir das quais esse poder instaura as disciplinas, a arquitetura respondeu com sua própria tentativa de desmaterialização, de forma a, por um lado, revelar as intimidades e permitir a penetração total dos mecanismos de coerção nos espaços, e por outro, como ferramenta de desmaterialização e dissimulação das próprias estruturas de poder. A observação dessa relação sugere que os períodos históricos durante os quais as estruturas de poder gozam de relativa estabilidade parecem ser propícios ao refinamento da produção arquitetônica, de forma a aperfeiçoar o exercício desse mesmo poder, seja sobre o espaço, seja sobre o movimento dos corpos no espaço. Em contraponto, os momentos nos quais as estruturas de poder sofrem abalos são aqueles em que tanto a prática da arquitetura como do planejamento urbano devem responder com transformações também estruturais. Historicamente, essa alternância alimenta tanto as próprias estruturas de dominação quanto a produção arquitetônica sua contemporânea, revelando, assim, as faces de ambas.

\section{Referências}

ALGRAND, Christine Pevitt. Madame de Pompadour, senhora da França. Rio de Janeiro: Objetiva, 2005.

ARAGON, Louis. O camponês de Paris. Rio de Janeiro: Imago, 1996 Letras, 2003. 
DEBORD, Guy. A sociedade do espetáculo. Rio de Janeiro: Contraponto, 1997.

DILLER, Elisabeth; SCOFFIDIO, Ricardo. Flesh: architectural probes. New York: Princeton Architectural Press, 1994.

ENGELS, Friedrich. A origem da família, da propriedade privada, do Estado. 2. ed. São Paulo: Centauro, 2004.

FORTY, Adrian. Objetos de desejo. São Paulo: Cosac \& Naify, 2007.

FOUCAULT, Michel. Microfísica do poder. 25. ed. São Paulo: Graal, 2008a.

FOUCAULT, Michel. Vigiar e punir. 25. ed. Petrópolis: Vozes, 2008b.

GOMBRICH, Ernst. A história da arte. 16. ed. Rio de Janeiro: LTC, 2000.

HAGEN, Rose-Marie; HAGEN, Rainer. Egipto: pessoas, deuses, faraós. Köln: Taschen Books, 1999.

HOBSBAWM, Eric J. A revolução francesa. São Paulo: Paz e Terra, 1996.

HOLLANDA, Frederico. O espaço de exceção. Brasília: Editora UnB, 2002.

HOUAISS, Antônio. Dicionário eletrônico da língua portuguesa. Rio de Janeiro: Objetiva, 2001.

LE CORBUSIER. Por uma arquitetura. 6. ed. São Paulo: Perspectiva, 2002.

LEFEBVRE, Henri. Espaço e política. Belo Horizonte: Editora UFMG, 2008.

LEFEBVRE, Henri. A revolução urbana. 2. reimp. Belo Horizonte: Editora UFMG, 2004.

REVEL, Judith. Foucault: conceitos essenciais. São Carlos: Claraluz, 2005.

REZENDE, Vera. Planejamento urbano e ideologia. São Paulo: Civilização Brasileira, 1982.

VASARI, GIORGIO. The lives of the most excellent painter, sculptors and architects. New York: Random House, 2006.

WOLFF, Sílvia Ferreira Santos. Jardim América: o primeiro bairrojardim de São Paulo e sua arquitetura. São Paulo: Imesp, 2001.

\section{Endereço para correspondência}

Gustavo Henrique Maciel Camargo

Rua Francisco Deslandes, 823/1002

30310-530 - Belo Horizonte - MG

ghmcamargo@gmail.com 
